\title{
Saberes e Fazeres da Docência na Licenciatura em Informática: Relato de Experiência das Ações do PIBID
}

\author{
Givanaldo Rocha de Souza ${ }^{2}$, Pauleany Simões de Morais ${ }^{1}$, Anna Raquel da S. \\ Marinho'$^{1}$, Jeanne Barbosa da Silva Bulcão ${ }^{1}$, Danylla de Medeiros Souza ${ }^{1}$
}
${ }^{1}$ Instituto Federal de Educação, Ciência e Tecnologia do Rio Grande do Norte - IFRN, Campus Natal Zona - Norte

${ }^{2}$ Instituto Federal de Educação, Ciência e Tecnologia do Rio Grande do Norte - IFRN, Campus Parnamirim

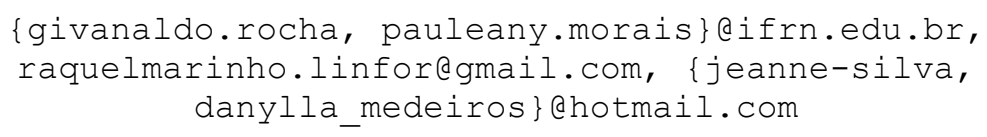

\begin{abstract}
This article reports didactic and pedagogical experiences lived by students of the Degree Course in Informatics from Federal Institute of Education, Science and Technology of Rio Grande do Norte, Campus Natal - North Zone, within the Institutional Scholarship Program Introduction to Teaching (PIBID). The methodology used was the action research concerning Computing and Education and focusing on teacher's education in Computing area as well as evaluating the performance of scholarships of teaching initiation in a Public School, located in North Zone of Natal/RN. As a result, we can evaluate the contributions of PIBID actions for teacher's education on Computing area, beyond the possibilities of pedagogical actions inherent to the computing education at public schools.
\end{abstract}

Resumo. Este artigo relata experiências didático-pedagógicas vivenciadas por bolsistas do Programa Institucional de Bolsas de Iniciação à Docência (PIBID) da Licenciatura em Informática do Instituto Federal de Educação, Ciência e Tecnologia do Rio Grande do Norte, Campus Natal - Zona Norte. Como metodologia, utilizou-se a pesquisa-ação sobre Informática e Educação, com foco na formação de professores na área da Computação, bem como o relato da atuação dos bolsistas em uma Escola Pública, localizada na Zona Norte de Natal/RN. Como resultado, avalia-se a contribuição do PIBID, subprojeto Informática, para a formação docente, além das possibilidades de ações pedagógicas inerentes ao ensino de computação na escola pública.

\section{Introdução}

Com os avanços promovidos pelas tecnologias oriundas da Computação, entende-se que as discussões sobre a profissionalização do professor de Informática ganharam destaque em meio às reflexões sobre sua atuação na escola. Esse profissional, em âmbito geral, sofre com as incertezas nas perspectivas de sua atuação no espaço escolar. Embora, diversos trabalhos apontem para mudanças dessa realidade, como é o caso de Nunes (2008), que reconhece os Cursos de Licenciatura em Computação como os responsáveis em formar professores capazes de levar o pensamento computacional para a sala de aula, disseminando-o, promovendo a inserção dos conceitos da Ciência da Computação na 
V Congresso Brasileiro de Informática na Educação (CBIE 2016)

Anais do XXII Workshop de Informática na Escola (WIE 2016)

Educação Básica. Entretanto, ainda há muitos desafios e divergências quanto a atuação desse profissional docente no espaço escolar.

Diante disso, esse artigo relata as experiências didático-pedagógicas vivenciadas por bolsistas do subprojeto Informática do Programa Institucional de Bolsas de Iniciação à Docência (PIBID) do Curso de Licenciatura em Informática do Instituto Federal de Educação, Ciência e Tecnologia do Rio Grande do Norte (IFRN), Campus Natal - Zona Norte, frente ao ensino e ao desenvolvimento de ações diversificadas no campo da Ciência da Computação. Dessa forma, as experiências apresentadas resgatam e fomentam novas discussões que dirimem e demostram possibilidades de atuação, saberes e fazeres específicos dos Licenciados em Informática.

Como fundamentação teórico-metodológica, desenvolve-se uma pesquisa-ação que conduz as discussões sobre Informática e Educação com foco na formação inicial de professores na área da computação, bem como o relato da atuação dos bolsistas em uma Escola Pública, localizada na Zona Norte de Natal/RN. Na fundamentação teórica, cabe destacar os conhecimentos científicos articulados tanto na área pedagógica quanto na área de informática para a formação inicial dos licenciandos. Como referencial teóricometodológico, utiliza-se uma revisão de literatura na qual podemos destacar o trabalho de Imbernón (2004) e Tardif (2010). Tais autores auxiliam nas reflexões sobre os processos de aprendizagem necessários à docência (constituição dos saberes docentes) e a formação inicial de professores. Outros autores tratam da necessidade de desenvolvimento do pensamento computacional, em que recebe destaque a autora Wing (2006).

Compreende-se as ações realizadas no PIBID de Informática como balizadoras de avanços e reflexões sobre a prática docente dos egressos, pois mostram-se como oportunidade significativa de pensar a ação docente, articulada a situações experienciais com atividades diversificadas para contribuir na formação inicial de professores, bem como constituir de maneira multidisciplinar e contextualizada ações pedagógicas necessárias ao ensino de computação nas escolas públicas, onde a prática desse ensino tem se tornado cada vez mais presente.

Na seção 2, são apresentadas as contribuições das ações do PIBID para a formação profissional docente. Na seção 3, realiza-se uma reflexão sobre o ensino da computação na educação básica e a formação docente. Na seção 4, são relatadas a metodologia utilizada e as experiências operacionalizadas pelos bolsistas do PIBID. Por fim, na seção 5, as considerações finais acerca do trabalho são apresentadas.

\section{Contribuições do PIBID na Formação Profissional Docente}

A Formação Profissional Docente representa um processo em que o sujeito constrói um conhecimento pedagógico especializado que deve ser vivenciado no espaço das instituições formadoras ou mesmo orientado por estas. Os estudos que investigam sobre a formação profissional mostram que o exercício profissional na realidade social, deve ser o foco, devido à intensa relevância do processo ação-reflexão--ação [Ramalho, Nuñez e Gauthier 2003].

Nessa perspectiva, as instituições educacionais devem ser consideradas conforme os seguintes aspectos: (a) para uma reconstrução da cultura escolar enquanto processo; (b) para propor a interdependência docente, ao invés do corporativismo profissional; (c) para propor a comunicação, ao invés do individualismo e isolamento; (d) para propor a autonomia, ao invés da dependência; e (e) para desenvolver a auto-regulação e a crítica colaborativa, ao invés da direção autoritária e externa [Imbernón 2004]. 
V Congresso Brasileiro de Informática na Educação (CBIE 2016)

Anais do XXII Workshop de Informática na Escola (WIE 2016)

Pode-se dizer que a formação centrada na escola envolve todas as condições necessárias para desenvolver os programas de formação, pois é o campo empírico que por excelência proporciona respostas às demandas da própria escola, como a elevação da qualidade do ensino e da aprendizagem em sala de aula, bem como deve ser o campo empírico para responder as necessidades das instituições superiores [Imbernón 2004].

Nesta perspectiva, o PIBID surgiu para aperfeiçoar e valorizar a formação de professores para a educação básica e desenvolver uma formação centrada na escola. Surge por meio da Portaria n. 72, de 9 de abril de 2010. A finalidade do programa é apoiar a iniciação à docência de estudantes de licenciatura plena das instituições de educação superior federais, estaduais, municipais e comunitárias sem fins lucrativos, visando aprimorar a formação dos educadores, valorizar o magistério e contribuir para a elevação do padrão de qualidade da educação básica [Brasil 2010].

O programa concede bolsas aos acadêmicos dos cursos de licenciatura participantes de projetos de iniciação à docência, desenvolvidos por Instituições de Educação Superior (IES), em parceria com escolas de educação básica da rede pública de ensino. O incentivo financeiro, aliado à possibilidade de desenvolver práticas docentes durante o curso, tem revelado importantes fatores para o sucesso do programa [Canan 2012]. Os alunos da iniciação à docência são inseridos no contexto das escolas públicas desde o início da sua formação acadêmica, para que desenvolvam atividades didático-pedagógicas, sob a orientação de um docente da licenciatura e de um professor da escola. Esse programa possibilita aos graduandos a experiência de conviverem com as escolas e de participarem de todos os seus espaços desde o início dos cursos de licenciatura, sendo um fator que influencia positivamente na formação dos acadêmicos, que nos semestres finais do curso farão estágios e se sentirão mais preparados para os desafios da docência. Esse processo, que envolve licenciandos, coordenadores e supervisores, gera um movimento dinâmico de formação recíproca em que tanto a escola quanto a IES aprendem e ensinam ao mesmo tempo, retroalimentando a relação entre teoria e prática.

A escola, sendo considerada como lugar de formação, nos permite vivenciar as contradições da própria atuação profissional, bem como compreender a relevância da fundamentação teórico-prática da docência. Mostra-se a importância de viabilizar ações que permitam aos discentes, que serão futuros professores, estarem inseridos em propostas pedagógicas que os permitam refletir sobre a prática docente em sua própria ação educativa. Além de permitir a construção de alternativas didático-pedagógicas mais viáveis à concretude real presente nas instituições educativas públicas.

\section{Ensino de Computação na Educação Básica e Formação Docente}

A formação docente para atuação profissional no ensino da computação traz a necessidade de refletir sobre as diversas possibilidades de pensar o desenvolvimento do pensamento e do raciocínio computacional atrelado a processos educacionais nos diversos níveis e modalidades da educação. Na discussão sobre pensamento computacional, Wing (2006) apresenta-se de forma pioneira, referindo-se as diversas probabilidades analíticas da computação.

Desse modo, o conceito defendido pela autora relaciona-se com o potencial da computação diante da necessidade de desenvolvimento do pensamento computacional em que se destina à resolução de problemas, abstração, decomposição, automação, simulação, modelagem e do pensamento recursivo, sequencial e paralelo. Mostra-se a relevância dos 
V Congresso Brasileiro de Informática na Educação (CBIE 2016)

Anais do XXII Workshop de Informática na Escola (WIE 2016)

estudos sobre pensamento computacional significativo à resolução de problemas do cotidiano.

O estudo apresentado por Bombasar et al. (2015) sobre o ensino de Computação procura evidenciar as principais ferramentas utilizadas para desenvolvimento do pensamento computacional diante de uma revisão de literatura nos diversos meios científicos entre os anos de 2006 a 2015. Nesse estudo, os autores apontam um acentuado interesse da comunidade científica pelo ensino do pensamento computacional na Educação Básica com ênfase em ferramentas que utilizam a Linguagem Visual de Programação, tais como: Scratch, App Inventor, Alice, Scalable Game Design (SGD), AgentSheet e Kodu. Observa-se que o ensino de Computação vem sendo repensado ao longo dos anos e exige uma formação docente que permita viabilizar as melhores estratégias de ensino para a disseminação do pensamento computacional, no sentido de conduzir uma aprendizagem significativa nos diversos níveis e modalidades de ensino.

Com intenso potencial de articular ações, discussões e debates das diversas áreas do conhecimento pode-se dizer que o desenvolvimento do raciocínio computacional deveria ser uma busca constante em processos educacionais orientadores da prática docente em computação. Isso significa inferir que a prática docente necessita de encaminhamentos pedagógicos, didáticos, metodológicos e conceituais na sistematização dos conhecimentos científicos próprios da Ciência da Computação. Diante do desenvolvimento cognitivo do sujeito, o raciocínio computacional pode ser considerado como "[...] capacidade de resolução de problemas de forma sistemática, usando dedução e abstração, habilidade muito trabalhadas na Ciência da Computação" [Ferreira et al. 2015, p. 257].

Matos (2013) analisa que a computação ao longo de sua história possui restrita tradição em estudar aspectos identitários de seus profissionais. Por consequência, tem se exigido uma formação cada vez mais especializada e dos que atuam na docência (bacharéis ou licenciados) uma qualificação pedagógica e formação técnica condizente a área da Computação. Confere-se a formação docente, seja inicial ou continuada, movimentos articulados entre as diversas áreas do conhecimento acadêmico-científico necessários ao ato educativo. Segundo Feldman (2014, p. 118):

\footnotetext{
$\mathrm{Na}$ docência interdisciplinar articulada ao contexto institucional, temos que considerar a questão da complexidade, multirreferencialidade que cerca a questão. Envolve vários campos de conhecimento em que se mostram conceitos, teoria proveniente de diversas ciências, bem como da filosofia-ética-moral que ao serem aprofundados explicitam a provisoriedade na busca da totalidade do ato de conhecer.
}

Pode-se colocar de um modo mais amplo a tecnologia como uma necessidade social da educação nas diversas modalidades e níveis de ensino, no sentido de vivenciar novas possibilidades de contextualizar a tecnologia com processos de ensino e aprendizagem, o que exige uma formação docente coerente a essas novas exigências. A discussão sobre as necessidades de mudanças no currículo da escola exige uma formação docente diferenciada que possa contemplar aspectos das transformações contextuais da própria sociedade, principalmente num mundo cada vez mais digital. Nesse caso, é preciso compreender e estabelecer novas bases da relação entre tecnologia e os processos de aprendizagem.

Todo processo educacional exige de o professor compreender seu papel de mediador no sentido de promover a internalização de determinados conhecimentos. Precisa saber oferecer aos seus alunos condições educacionais de realização qualificada do ato de conhecer. Com efeito, a "[...] mediação pode assumir diferentes sentidos. Um deles diz respeito à harmonização de conflitos entre interesses diferentes entre si, com o objetivo de diminuir as diferenças, de unificar as forças ou de equilibrá-las" [Matos 2013, p. 79]. Nessa 
V Congresso Brasileiro de Informática na Educação (CBIE 2016)

Anais do XXII Workshop de Informática na Escola (WIE 2016)

conjuntura, a mediação configura-se como possibilidade de harmonizar os interesses no ato de conhecer no interior do processo educacional em que o docente precisa orientar as ações necessárias ao processo de ensino-aprendizagem.

\section{Relato de Experiência}

Ao destacar até o momento os estudos desencadeados sobre as particularidades da formação de professores e suas repercussões complexas no ensino da Computação, apresenta-se a possibilidade de contribuir para o delineamento teórico-metodológico de uma investigação-ação-participativa, que articule estudos e planejamento acadêmicos científicos (produção) com atuação em atividades de ensino-pesquisa-extensão.

Diversos autores reconhecem Kurt Lewin (estudioso das questões psicossociais), nos anos de 1940, como aquele que concebeu a investigação-ação. Em 1944, o referido investigador já descrevia o processo de pesquisa-ação, indicando um ciclo vital: planejar, agir, descrever e avaliar [Tripp 2005].

Desse modo, trata-se de um tipo de investigação social concebida e realizada em estreita associação com uma ação ou proposição para um problema coletivo, no qual investigadores e outros sujeitos participam, interagem, opinam e discutem de modo coletivo, democrático e criticamente no desenvolvimento da investigação. Nesse caso, refere-se a uma vivência realizada em uma escola pública participante do PIBID, que envolve uma via de mão dupla tanto de contribuição à formação docente dos licenciando de Informática, quanto de uma possibilidade de atuação com o ensino de computação nessa realidade. Nessa experiência, as possibilidades aplicadas foram, respectivamente, a Computação Desplugada e a Iniciação à Programação utilizando o Scratch, descritas nas seções a seguir.

\subsection{Computação Desplugada}

As experiências operacionalizadas pelos bolsistas do PIBID, subprojeto Informática, na perspectiva da Computação Desplugada, demonstram que o ensino de fundamentos da computação por meio dessa estratégia de ensino está de acordo com os estudos realizados e sistematizados por Bell et al. $(2011,2012)$ no livro Computer Science Unplugged (Computação Desplugada, em português), sendo uma alternativa ao ensino "robotizado" dos conceitos da Ciência da Computação.

A Computação Desplugada consiste em ensinar os fundamentos da computação, por meio de atividades, sem o uso do computador [Bell et al. 2011]. Empregada em diversos países, tem despertado o interesse de professores e pesquisadores [Scaico et al. 2012; Souza et al. 2010]. Acessível para as pessoas de todas as idades, desde o ensino fundamental até o ensino superior, com diferentes conhecimentos e experiências, as "atividades desplugadas" são passíveis de aplicação em localidades remotas e em espaços que apresentam pouca infraestrutura física. Destaca-se ainda, sua independência de recursos de hardware ou software [Bell et al. 2011]. Nesse contexto, a Computação Desplugada surge como um meio de culminar as ações realizadas pelo PIBID de Informática nas escolas.

Ocorrido no dia 27 de novembro de 2015, o "Dia da Informática", atraiu professores, estudantes e toda a comunidade escolar, construindo vínculos e ampliando parcerias entre o PIBID e a escola. O evento centrou ações também de outros subprojetos do PIBID que atuam na escola, além do subprojeto Informática. As ações desenvolvidas nas oficinas de Computação Desplugada possibilitaram o trabalho em equipe, bem como, a 
resolução de problemas, estimulando a criatividade. Atividades dessa natureza são relatadas com sucesso na literatura, cujas experiências são realizadas com alunos de escolas públicas [Scaico et al. 2012; Bezerra 2014]. O trabalho de Barbosa et al. (2015) relata a aplicação da Computação Desplugada aplicada por bolsistas do PIBID da Licenciatura em Computação da UFPB, Campus Rio Tinto, por meio de gincanas em escolas estaduais com alunos do $1^{\circ}$ ano do ensino médio.

No PIBID, subprojeto Informática, as ações no campo da computação desplugada fazem parte da proposta anual dos bolsistas, que devem planejar ações na perspectiva de mobilizar as escolas quanto aos saberes e fazeres docentes dos Licenciados em Informática. Para o "Dia da Informática" foram planejadas duas oficinas desplugadas, ilustradas na Figura 1. A primeira, "Contando os Pontos" faz referência à atividade de mesmo nome, descrita por Bell et al. (2011). Segundo os autores, essa atividade permite a mediação de conceitos básicos da Ciência da Computação, como por exemplo, do sistema numérico binário, utilizado nos computadores digitais.

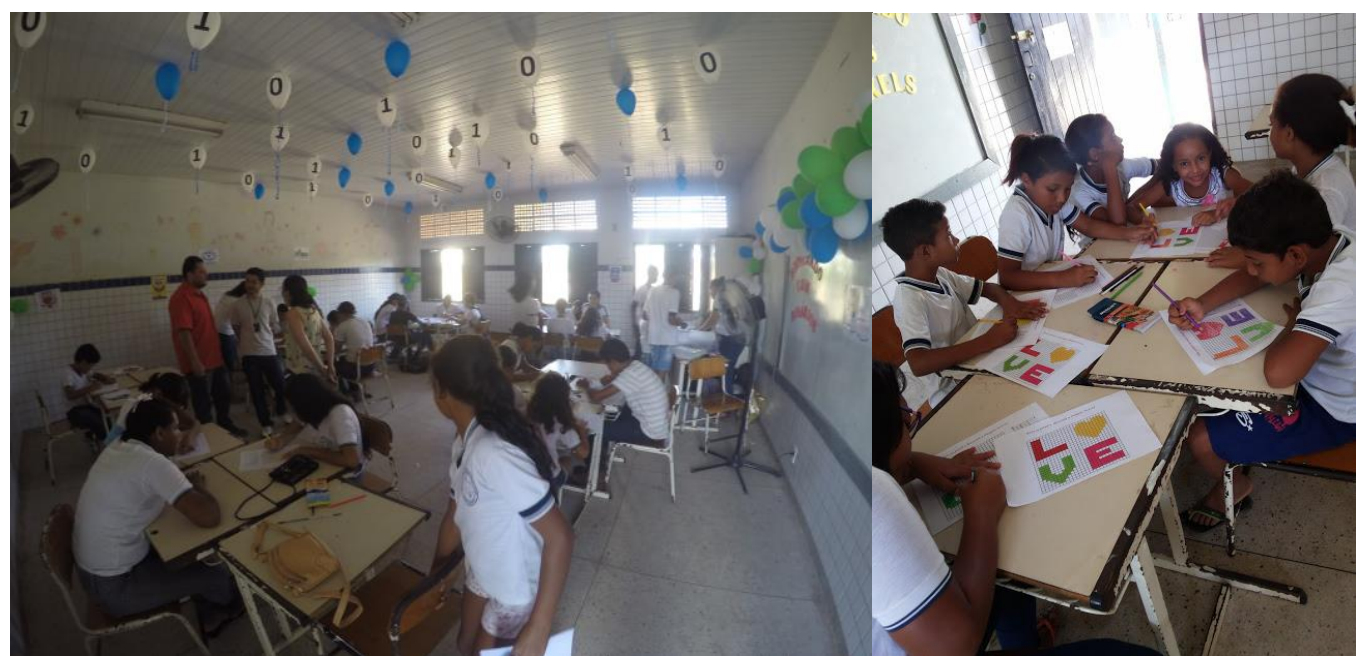

Figura 1. Oficinas de Computação Desplugada: "Contando Pontos" e "Colorindo com Números" (Fonte: PIBID de Informática, 2015)

A oficina, construída a partir das orientações descritas por Bell et al. (2011), trabalhou duas atividades relacionadas aos bits (dígitos binários: 0 e 1). A atividade "Contando os pontos" apresentou, como mencionado, a linguagem binária, enquanto a segunda, "Colorindo com números", conduziu as discussões de como o computador armazena e organiza as imagens.

Para a realização das oficinas, foi planejada e criada uma atmosfera que remetesse aos números binários, em que representações de 0's e 1's foram dispostas em toda sala de aula. Materiais comuns à decoração lúdica foram resgatados: bolas, cartolinas, papéis coloridos, dentre outros que criam um ambiente alegre e divertido. As bolas foram utilizadas na decoração, painéis foram criados com cartolinas a serem preenchidas com os desenhos pintados pelos estudantes. Nos papéis coloridos, foram impressas imagens que serviram de referência para os estudantes.

A escola onde ocorreu o "Dia da Informática" está localizada na Zona Norte de Natal/RN, em uma região periférica. Assim como outras escolas da rede pública brasileira, passa por problemas de infraestrutura, carece de professores e o espaço destinado à sala de Informática começou a ser utilizado com frequência após a chegada do PIBID. Os 
V Congresso Brasileiro de Informática na Educação (CBIE 2016)

Anais do XXII Workshop de Informática na Escola (WIE 2016)

participantes da oficina são moradores do entorno da escola, estudantes do ensino fundamental. Grande parte dos participantes já haviam frequentado aulas de Informática básica na escola, também promovidas pelos bolsistas do PIBID de Informática. Por essa razão, esperava-se que, ao término da oficina de computação desplugada, os participantes pudessem ter um "novo" olhar sobre a informática, despertando maior interesse pela área.

Os participantes da oficina demostraram, inicialmente, pouco interesse na atividade. Porém, à medida em que os bolsistas foram explicando a proposta da oficina, essa primeira impressão foi se transformando em curiosidade e em reconhecimento das próprias limitações frente às dificuldades presentes na atividade, que provocava conhecimentos prévios no campo da Matemática.

Para avaliação da oficina, foram utilizadas duas técnicas: a observação sistemática e o questionário, que se mostraram fundamentais para a compreensão dos resultados dessa ação. O questionário, entregue aos estudantes no início da atividade, continha duas perguntas, uma fechada e outra aberta. O questionário subsidiou as ponderações dos bolsistas durante as reflexões a respeito da ação. Para os bolsistas do PIBID de Informática, ações como essas nas escolas públicas entre outras contribuições, não só incentivam o ensino de computação nas escolas públicas, como também estimulam o raciocínio e a criatividade dos estudantes.

Participaram da oficina aproximadamente 50 estudantes. No entanto, apenas 13 responderam ao questionário. Quando questionados "Como você avalia esta oficina?", 12 participantes avaliaram como "ótima", apenas um avaliou como "regular". Na observação dos bolsistas, essa avaliação positiva é significativa, pois aponta a necessidade de outras ações semelhantes. Foi observado que as atividades permitiram aos participantes perceberem suas limitações e se colocarem na defensiva, alguns até sugerindo na resposta da segunda "pergunta", quando mobilizados a sugerir melhorias à oficina, que "desenhos mais fáceis" deveriam ser inseridos, enquanto outros pediram maior diversidade de desenhos.

$\mathrm{Na}$ perspectiva da docência, aos bolsistas do PIBID, essa experiência provou desenvolver atitudes e valores para a boa regência da sala de aula. Assim como permitiu a mobilização de saberes docentes específicos dos Licenciandos de Informática, que segundo Tardif [2010], são saberes plurais, oriundos da formação profissional e de saberes disciplinares, curriculares e experienciais.

\subsection{Iniciação a Programação Utilizando o Scratch}

Desenvolvido pelo Lifelong Kindergarten Group (LLK), grupo de pesquisa do MIT Media $L a b$, o ambiente introdutório de ensino Scratch foi criado com o propósito de introduzir a programação de maneira fácil e rápida para aqueles que não possuem nenhum tipo de experiência no assunto [Maloney et al. 2010]. Para tanto, o processo de ensinoaprendizagem, com a utilização do Scratch, ocorre através de uma linguagem de programação visual que permite a manipulação de mídias, tais como imagens e músicas, para a criação, por exemplo, de histórias interativas, de jogos ou de animações [Maloney et al. 2010; Maloney et al. 2008].

Nos estudos de Bombasar et al. (2015), aponta-se que o Scratch é utilizado frequentemente em atividades de iniciação à programação no Ensino Fundamental. Nesse caso, justifica-se o uso dessa ferramenta na realidade e no contexto ao qual se realizou a oficina de Scratch na escola pública de atuação do PIBID, ocorrida no "Dia da Informática". Nesse contexto, a oficina teve como objetivo apresentar aos estudantes do 
V Congresso Brasileiro de Informática na Educação (CBIE 2016)

Anais do XXII Workshop de Informática na Escola (WIE 2016)

ensino fundamental da escola que não haviam participado da oficina de Computação Desplugada, o software Scratch. Assim, esperava-se estimular a curiosidade dos adolescentes quanto à programação e ao desenvolvimento do pensamento computacional defendido por Wing [2006]. As observações dos bolsistas que mediaram a oficina apontam que os estudantes que participaram dessa atividade conseguiram compreender como fariam para orientar o personagem do Scratch, bem como se mostraram interessados durante as orientações dos bolsistas. Na figura 2, é mostrado o ambiente da oficina, bem como os alunos e os bolsistas do PIBID em ação.

A escola possui um laboratório de Informática com 10 computadores em que há horários reservados para a atuação dos bolsistas do PIBID de Informática. Os estudantes participantes da oficina foram conduzidos ao laboratório para uma prática de produção de jogos educacionais, com introdução de conceitos necessários à iniciação a programação. Os participantes tiveram a oportunidade de criar seus jogos e interagir entre eles. A turma consistiu de 10 alunos do ensino fundamental, de diferentes séries e idades, pois o prérequisito foi apenas "querer aprender".
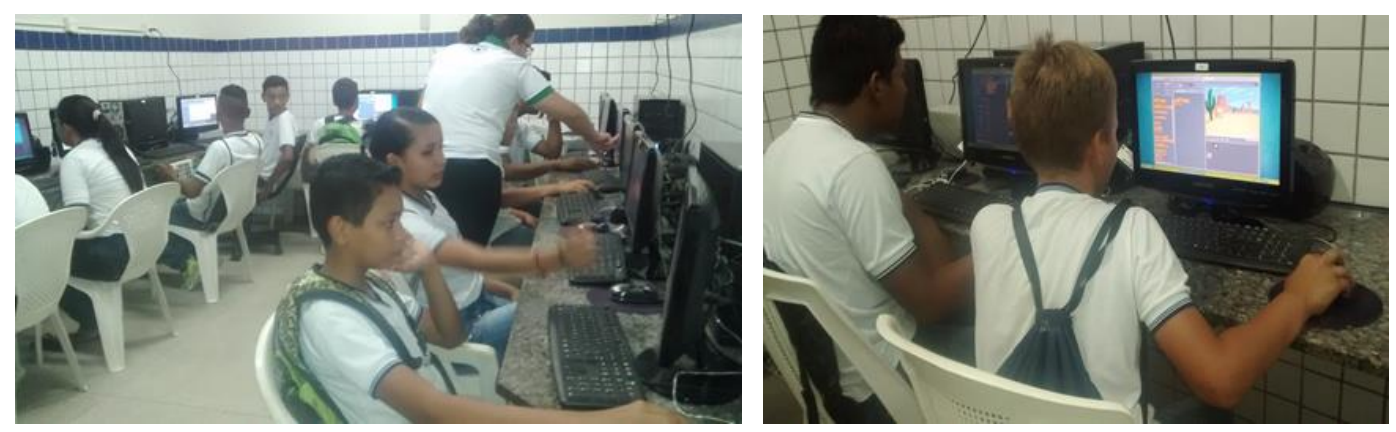

Figura 2. Oficina de Scratch (Fonte: PIBID de Informática, 2015)

O uso do Scratch tem possibilitado aos alunos a vivência de práticas pedagógicas que oportunizam o desenvolvimento de um conjunto de habilidades voltadas à concentração, abstração e interação. Dessa forma, com os resultados positivos obtidos junto à oficina, foram pensadas outras oficinas de programação para os estudantes da escola, de modo a continuar essas experiências. Numa perspectiva interdisciplinar, no planejamento das oficinas de 2016, buscou-se articular o uso do laboratório e o ensino de programação com outras áreas do conhecimento, inicialmente com Português, Matemática, Química e Biologia.

\section{Considerações Finais}

As ações do PIBID enquanto mobilizadoras de conhecimentos acadêmicos, teóricos e práticos, têm possibilitado aos bolsistas da Licenciatura em Informática a compreender a extensão de seus saberes e as possibilidades de sua atuação no espaço escolar. Na dimensão dos fazeres docentes, as práticas vivenciadas por meio das ações realizadas constroem e alimentam a epistemologia desse curso.

Por meio da pesquisa-ação realizada, perceberam-se as repercussões acerca do ensino da Computação e as possíveis contribuições dessa área do conhecimento para as demais áreas, culminando em atividades articuladas que corroboraram com uma ação 
V Congresso Brasileiro de Informática na Educação (CBIE 2016)

Anais do XXII Workshop de Informática na Escola (WIE 2016)

participativa, envolvendo graduandos em formação inicial docente, professores, estudantes da Educação Básica e a comunidade escolar.

As perspectivas do papel do professor de Informática estão sendo ampliadas, visto que à medida que novas metodologias são demonstradas, a sociedade, principalmente a comunidade escolar, percebe a importância desse profissional para a educação.

As experiências com o uso da Computação estão sendo imprescindíveis, tanto para a formação dos futuros Licenciados em Informática quanto para a Escola Pública, que tem uma função social a cumprir. Compreender as possibilidades e a importância da utilização dos recursos computacionais é o primeiro passo para que o laboratório de Informática, que antes estava em desuso, apresente-se como uma nova possibilidade de espaço de aprendizagem na escola pública.

A partir do trabalho desenvolvido, pode-se inferir que é possível a operacionalização de um trabalho didático-pedagógico significativo nas Escolas de Educação Básica com a utilização de recursos computacionais, seja por meio da Computação Desplugada ou de Softwares Educacionais. Espera-se que ações como a relatada sejam perpetuadas em outras atuações, que venham a ser conduzidas nas escolas públicas, promovendo a articulação do uso do laboratório para as diversas áreas do conhecimento.

\section{Referências}

Barbosa, A. V. S., Pereira Neto, A. F., Oliveira, R. N. R., Costa, T. L. S., Araújo, A. L. S. O. e Costa, F. V. S. (2015) "O ensino de conceitos computacionais para alunos do ensino médio: relato de experiência de uma gincana e das estratégias utilizadas pelos alunos na resolução das atividades desplugadas", Anais do XXXV Congresso da Sociedade Brasileira de Computação, XXIII Workshop sobre Educação em Computação (WEI 2015), ISSN 2175-2761.

Bell, T., Witten, I. e Fellows, M. (2011) "Computer Science Unplugged - Ensinando Ciência da Computação sem o uso do Computador", Tradução de Luciano Porto Barreto. Disponível em: http://csunplugged.org/wpcontent/uploads/2014/12/CSUnpluggedTeachers-portuguese-brazil-feb-2011.pdf/. Acesso em 20/10/2015.

Bell, T., Whitten, I. e Fellows, M. (2012) “Computer Science Unplugged”, Universidade de Canterbury, Nova Zelândia, 2007. 105 p. Disponível em: Acesso em: 12 Fev. 2012.

Bezerra, F. (2014) "Bem mais que os Bits da Computação Desplugada", Anais do III Congresso Brasileiro de Informática na Educação, XX Workshop de Informática na Escola (WIE 2014).

Bombasar, James R.; Santiago, R., Miranda, E. M. e Raabe, A. L. A. (2015) "Ferramentas para o ensino-aprendizagem do pensamento computacional: onde está Alan Turing?”, IV Congresso Brasileiro de Informática na Educação, X Conferência Latino-Americana de Objetos e Tecnologias de Aprendizagem (CBIE-LACLO). In: Anais do XXI Workshop de Informática na Escola. Maceió - AL.

Brasil, Ministério da Educação, Conselho Nacional de Educação. Portaria n. 72, de 9 de abril de 2010. Disponível em: <http://www.capes.gov.br/>. Acesso em: 17 mai. 2014.

Canan, S. R (2014) "PIBID: promoção e valorização da formação docente no âmbito da Política Nacional de Formação de Professores”, Rev. Form. Doc., Belo Horizonte, v. 04, 
V Congresso Brasileiro de Informática na Educação (CBIE 2016)

Anais do XXII Workshop de Informática na Escola (WIE 2016)

n. 06, p. 24-43, jan./jul. 2012. Disponível em http://formacaodocente.autenticaeditora.com.br. Acesso em: 17 mai. 2014.

Feldman, M. G. (2014) Formação docente e contexto institucional. In: FAZENDA, Ivani Catarina A (Org.); GODOY, Herminia Prado (Coord. Técnica). Interdisciplinaridade: pensar, pesquisar, intervir. São Paulo: Cortez.

Ferreira, A. C. C., Melhor, A., Barreto, J. S., Paiva, L. F. e Matos, E (2015) "Experiência prática interdisciplinar do raciocínio computacional em atividades de computação desplugada na Educação Básica", IV Congresso Brasileiro de Informática na Educação, $\mathrm{X}$ Conferência Latino-Americana de Objetos e Tecnologias de Aprendizagem (CBIELACLO). In: Anais do XXI Workshop de Informática na Escola. Maceió - AL.

Imbernón, F. (2004) "Formação docente e profissional: formar-se para a mudança e a incerteza", 2 ed. São Paulo: Cortez.

Maloney, J., Peppler, K., Kafai, B. Y., Resnick, M. e Rusk, N. (2008) "Programming by choice: Urban Youth Learning Programming with Scratch", Proceedings do 39th SIGCSE'08, Portland, USA, p. 367-371.

Maloney, J., Resnick, M., Rusk, N., Silverman, B. e Eastmond, E. (2010) "The scratch programming language and environment", ACM Transactions on Computing Education, vol. 10, n. 4.

Matos, E. (2013) "Dialética da Interação Humano-Computador: tratamento didático do diálogo midiatizado", Tese (Doutorado em Educação). Universidade de São Paulo, São Paulo/SP, Brasil.

Identidade profissional docente e o papel da interdisciplinaridade no currículo de licenciatura em computação. Revista Espaço Acadêmico, Maringá, PR, v. 13, n. 148, set. 2013.

Matos, E., Oliveira, E. S. G. e Cruz, F. O. (2011) "Currículo e tecnologia - do raciocínio semiótico abdutivo em Peirce aos conhecimentos prévios em Vygotsky”, Revista eCurriculum. São Paulo-SP, vol. 7, núm. 2, agosto, p. 1-22.

Nunes, D. J. (2008) “Ciência da Computação na Educação Básica”, Jornal da Ciência, 9.

Ramalho, B. L., Nuñez, I. B. e Gauthier, C (2003), Formar o professor, profissionalizar o ensino: perspectivas e desafios, Porto Alegre: Sulina.

Scaico, P., Henrique, M., Cunha, F. e Alencar, Y. (2012) "Um Relato de Experiências de Estagiários da Licenciatura em Computação com o Ensino de Computação para Crianças". Revista Renote: Novas Tecnologias na Educação, v. 10, n. 3.

Tardif, M. (2010) “Saberes Docentes e Formação Profissional”, Petrópolis - RJ: Vozes.

Tripp, D. (2005) "Pesquisa-ação: uma introdução metodológica. Educação e investigação", São Paulo, v. 31, n. 3, p. 443-466.

Wing, J. M. (2006) "Computational Thinking”, Communications of the ACM, vol. 49, n. $13,2006$. 